\title{
Resenha
}

\section{A morte inventada: depoimentos e análise sobre a alienação parental e sua síndrome ${ }^{1}$}

\section{Fading away: testimonials and analysis concerning parental alienation syndrome}

\author{
Ana Ludmila Freire COSTA²
}

\begin{abstract}
A alienação parental é um fenômeno cada vez mais reconhecido entre profissionais dos meios jurídicos e psicossociais. O termo foi cunhado pela primeira vez por Gardner (1985), referindo-se à situação em que um genitor faz alterar a percepção que a criança tem sobre o outro genitor, objetivando afastá-los. Isso acontece em geral após a separação conjugal e como forma de vingança do ex-companheiro, seja por ter sido abandonado, traído ou se frustrado em relação à vida conjugal.
\end{abstract}

Diante das graves consequências de tais práticas para o pleno desenvolvimento da criança e visando esclarecer o fenômeno entre as famílias, foi lançado em 2009 o vídeo "A morte inventada". Trata-se de um longametragem elaborado sob o formato de documentário, que traz depoimentos de pais, filhos e profissionais envolvidos com o tema.

O título faz referência a um crime intencional e a ideia é reiteradamente mencionada ao longo do vídeo, quando os depoentes alinham o conceito de alienação parental a "matar a imagem do outro dentro de alguém". A denominação dada pelo diretor tem sido considerada muito adequada - tamanha a gravidade do fenômeno.
Nesse ponto, é mister diferenciar os dois termos comumente confundidos: segundo Darnall (1999), enquanto a alienação parental refere-se ao processo de afastamento empreendido pelo genitor; a síndrome de alienação parental diz respeito às consequências emocionais e comportamentais apresentadas pela criança vítima do processo.

O tema do documentário não poderia ser mais pertinente, já que questões envolvendo relações conjugais e parentais têm sido recorrentes nos noticiários nacionais, como a guarda compartilhada, a Nova Lei do Divórcio e o próprio projeto de lei que objetiva regular a atuação dos genitores em relação à Síndrome da Alienação Parental. Assim, percebe-se que os conflitos familiares estão, cada vez mais, extrapolando o limite do privado e alcançando determinações judiciais. E isso porque, na grande maioria das vezes, a sociedade recorre ao Judiciário em função da inabilidade para resolver os próprios conflitos ou da impossibilidade de se chegar a arranjos consensuais.

Foi a partir da vivência dessa situação que o diretor Alan Minas sentiu-se impulsionado a criar o documentário. Esse é seu primeiro longa-metragem,

$\boldsymbol{\nabla \nabla \nabla v}$

1 Minas, A. (Diretor) (2009). A morte inventada: alienação parental [Filme-vídeo]. Niterói, Caraminholas Produções.

2 Tribunal de Justiça de Pernambuco, Centro de Apoio Psicossocial. R. João Fernandes Vieira, 405, Boa Vista, 50710-400, Recife, PE, Brasil. E-mail: <analudmila@gmail.com>. 
tendo em seu currículo o roteiro e direção de cinco curtas-metragens, dois dos quais premiados em festivais nacionais.

Segundo Minas, o objetivo da produção é disseminar, da forma mais ampla possível, o assunto entre pais e profissionais, sejam eles operadores do Direito, equipes psicossociais ou médicos. De fato, a divulgação tem sido maciça, com exibição em diversos locais do país, sendo sempre seguida por palestras e debates. Além disso, junto ao lançamento do Disco Digital Versátil (DVD), foi disponibilizado no site < http:// www.amorteinventada.com.br> consideravelmente rico, que traz informações sobre a síndrome de alienação parental e depoimentos de pais que vivenciam o fenômeno.

No documentário, a articulação entre a teoria sobre a síndrome, explicada pelos profissionais, e a prática vivenciada pelas famílias depoentes é feita de forma coerente e bem estruturada. Para auxiliar essa conexão, o diretor faz uso de um recurso ficcional, em que durante a narração do texto, redigido e realizada por ele próprio, são apresentadas imagens de ambientes vazios, ainda que em funcionamento, como parque infantil, praia, jardim e labirinto de concreto, o que imprime um tom melancólico e solitário à produção, sentimento muito próximo daquele vivenciado pelos pais vítimas de alienação parental.

O roteiro traz sete casos, em que pais e filhos que se identificaram com as características da síndrome relatam detalhes de suas histórias e seus dramas. Chama atenção a presença da única mulher depoente como tendo sofrido alienação parental. De fato, de acordo com Pinho (2009), é significativamente mais comum deparar com casos de mulheres que praticam a síndrome de alienação parental contra seus ex-cônjuges/companheiros, considerando-se o percentual de mais de 90\% das guardas serem atribuídas às genitoras.

Dentre os casos apresentados, alguns se destacam, seja pela forte emoção transmitida pelos depoentes, seja pelos inimagináveis recursos utilizados pelos alienadores, seja ainda pelo grau de desgaste das relações familiares.

Um dos casos refere-se à atitude da genitora em relação às filhas, marcada por sentimento de posse e necessidade de controle, aspecto considerado típico de um genitor alienador (Associação de Pais e Mães

280 Separados, 2007; Fonseca, 2006; Magalhães, 2009).
Destaca-se ainda o afastamento causado pelo genitor entre a ex-esposa e o filho, que conta que "só conseguiu dar um beijo no rosto do filho quando este tinha 18 anos", bem como o relato de um pai, que precisou recorrer a uma ação policialesca hollywoodiana para buscar as crianças, mesmo de posse do documento oficial que lhe concedia a guarda.

Contudo, sem dúvida, o relato mais comovente é feito por uma jovem que passou 11 anos sem conviver com o pai, com quem retomou o contato recentemente. Ela lembra da obrigação que sentia de se aliar à genitora para agredir o pai, e ao fim do filme fica claro o impacto psicológico sofrido. Esses sentimentos demonstrados pela depoente foram debatidos por Silva (2010), que aponta que é comum a criança estabelecer um pacto de lealdade com o guardião, em função da dependência emocional e material.

O filme ainda apresenta dois casos de falsas denúncias de abuso sexual, talvez o sintoma mais crítico da alienação parental e cada vez mais comum entre as famílias desfeitas. Nesses casos, a justiça tem como procedimento afastar o possível abusador, imediatamente, até a conclusão do inquérito. Como, em geral, a investigação é demorada, o vínculo entre o sujeito acusado e o filho é perdido. Percebe-se que, quanto a esta questão, ainda há muito no que avançar, a fim de preservar a integridade da criança, mas também considerando a hipótese da falsidade da denúncia.

Deixando de lado os depoimentos das famílias, o documentário passa a analisar a participação dos profissionais da área de Psicologia, Direito e Serviço Social, com comprovada experiência em conflitos familiares, o que lhes permite pontuar aspectos peculiares. É esclarecido, por exemplo, que muitas vezes a alienação pode acontecer ainda na vigência da relação conjugal, e que as estratégias utilizadas pelo alienador podem ser bem sutis, como fazer a proposta de regulamentação de visitas não para valorizar o contato do filho com o outro genitor, mas para manter a situação sob seu controle.

Além de contribuir para esclarecer a temática em questão, os profissionais reavaliam suas práticas, reconhecendo, por exemplo, que ainda não há um preparo por parte das equipes psicossociais e dos operadores do Direito para lidar com o fenômeno.

Algumas críticas tecidas pelos familiares reforçam essa assertiva. Foi mencionada a realização de pare- 
ceres psicossociais baseados na escuta de apenas um dos lados da família, em geral o alienador, quando já se sabe que a escuta parcial e ingênua é descabida e nefasta nesse contexto. Sobre perícia psicológica no contexto da justiça, a literatura é vasta [Brito (2005), Cruz, Maciel e Ramirez (2005), França (2004), Rovinsk (2007) e Shine (2005)], não devendo, portanto, ainda ser passível de equívocos dessa natureza.

O filme é concluído com um dilema não resolvido: quais as medidas mais apropriadas para lidar com a síndrome de alienação parental? Alguns depoentes questionam a superficialidade com que são tratados os casos e, principalmente, a condescendência com que a justiça trata os alienadores. De fato, a discussão fundamentada a esse respeito ainda é incipiente no Brasil, com apenas algumas breves indicações (Magalhães, 2009; Vicentin, 2009). No entanto, no exterior, a busca por alternativas tem sido mais enfática, a exemplo dos estudos de Gardner (2002), Lowenstein (2008) e Palmer (2002).

Os autores citados são unânimes em aconselhar a não se assegurar na palavra da criança quando esta diz que não quer conviver com o genitor ausente. Sugerem, por outro lado, que o genitor afastado deve perseverar no esforço de estabelecer e manter contato com o filho, mesmo sentindo a rejeição constante, humilhante e desmoralizante.

As alternativas arroladas são o encaminhamento do alienador para psicoterapia e/ou a punição na forma da lei (detenções e/ou multas).

Sobre a questão da guarda e visitação, os estudos indicam, em um primeiro momento, a mediação entre as partes a fim de torná-las conscientes dos direitos e deveres concernentes aos filhos. Nos casos em que não se percebe a evolução do alienador na colaboração para reversão do fenômeno, os autores sugerem que a criança seja retirada da influência do mesmo, e que a guarda seja revertida em favor do alienado. Se a síndrome já estiver instalada e a vítima apresentar alto grau de resistência à convivência com o genitor alienado, é indicado que ela seja temporariamente encaminhada a um local neutro.

O documentário se encerra questionando as sequelas que o fenômeno causa na história de vida das pessoas, trazendo, assim, uma ampla abordagem sobre a alienação parental. Não há dúvida de que o filme não só ensina sobre a temática, mas leva à reflexão sobre as relações familiares modernas e o que se tem feito delas. E isso da forma mais cruel possível, porém realista, que é através da experiência vivida, da dor sofrida e das esperanças perdidas.

\section{Referências}

Associação de Pais e Mães Separados. (2007). Síndrome da alienação parental e a tirania do guardião. Porto Alegre: Equilíbrio.

Brito, L. M. T. (2005). Temas de psicologia jurídica. Rio de Janeiro: Relume-Dumará.

Cruz, R. M., Maciel, S. K., \& Ramirez, D. C. (Orgs.). (2005). O trabalho do psicólogo no campo jurídico. São Paulo: Casa do Psicólogo.

Darnall, D. (1999). Parental alienation conference. Retrieved March 2, 2010, from < www.fact.on.ca>.

Fonseca, P. M. P. C. (2006). Síndrome de alienação parental. Pediatria São Paulo, 28 (3), 162-168.

França, F. (2004). Reflexões sobre psicologia jurídica e seu panorama no Brasil. Psicologia: Teoria e Prática, 6 (1), 73-80.

Gardner, R. (1985). Recent trends in divorce and custody litigation. Academy Forum, 29 (2), 3-7.

Gardner, R. (2002). Parental alienation syndrome vs. parental alienation: which diagnosis should evaluators use in child-custody disputes? American Journal of Family Therapy, 30 (2), 93-115.

Lowenstein, L. F. (2008). What can be done to reduce the implacable hostility leading to parental alienation in parents? Justice of the Peace, 172 (12), 185-187.

Magalhães, M. V.O.C. (2009). Alienação parentale sua síndrome: aspectos psicológicos ejurídicos. Recife: Bagaço.

Palmer, S. E. (2002). Custody and access issues with children whose parents are separated or divorced. Canadian Journal of Community Mental Health, (4 Suppl), 25-38.

Pinho, M. A. G. (2009). Alienação parental: histórico, estatísticas, projeto de lei 4053/08 \& jurisprudência completa. Recuperado em março 2, 2010, disponível em <www. conteudojuridico.com.br>.

Rovinski, S. L. R. (2007). Fundamentos da perícia psicológica forense. São Paulo: Vetor.

Shine, S. (2005). Avaliação psicológica elei. São Paulo: Casa do Psicólogo.

Silva, D. M. P. (2010). Guarda compartilhada e síndrome da alienação parental: o que é isso? Campinas: Autores Associados.

Vicentini, M. R. C. (2009). Síndrome da alienação parental. Recuperado em março 2, 2010, disponível em <http:// www.conteudojuridico.com.br>.

Recebido em: 6/4/2010

Aprovado: 12/2/2011 
